\title{
Early spot sign is associated with functional outcomes in primary intracerebral hemorrhage survivors
}

\author{
Wen-Che Tseng ${ }^{1}$, Yu-Fen Wang ${ }^{2}$, Tyng-Guey Wang ${ }^{1,3}$ and Ming-Yen Hsiao ${ }^{1,3^{*}}$ (D)
}

\begin{abstract}
Background: The computed tomography angiography (CTA) spot sign is a validated predictor of hematoma expansion and 30-day mortality in intracerebral hemorrhage (ICH). However, whether the spot sign predicts worse functional outcomes among ICH survivors remains unclear. This study investigated the frequency of the spot sign and its association with functional outcomes and length of hospital stay among $\mathrm{ICH}$ survivors.

Methods: This was a retrospective analysis of consecutive patients with primary ICH who received CTA within $24 \mathrm{~h}$ from presentation to admission to the emergency department of a single medical center between January 2007 and December 2017. Patients who died before discharge and those referred from other hospitals were excluded. CTAs with motion artifacts were excluded from the analysis. The presence of a spot sign was examined by an experienced neuroradiologist. Functional outcomes were determined based on the modified Rankin Scale (mRS) score and Barthel Index (BI). Severe dependency in activities of daily living (ADL) was defined as BI of $\leq 60$ and severe disability as an $\mathrm{mRS}$ score of $\geq 4$. Odds ratio (OR) and multiple linear regression were used as measures of association.
\end{abstract}

Results: In total, 66 patients met the inclusion criteria, of whom 9 (13.64\%) were positive for a spot sign. No significant differences were observed in baseline characteristics between patients with and without a spot sign. Patients with a spot sign tended to be severely dependent in ADL at discharge $(66.67 \%$ vs $41.07 \% ; \mathrm{OR}=2.87 ; p=$ 0.15 ) and were more likely to require ICH-related surgery (66.67\% vs $24.56 \% ; \mathrm{OR}=6.14 ; p=0.01)$. In multiple linear regression, patients with a higher spot sign score had a significantly longer hospital stay (coefficient $=9.57 ; 95 \%$ $\mathrm{Cl}=2.11-17.03 ; p=0.013)$.

Conclusions: The presence of a spot sign is a common finding and is associated with longer hospital stay and possibly worse functional outcomes in $\mathrm{ICH}$ survivors.

Keywords: Intracerebral hemorrhage, Spot sign, Functional outcome, Prognosis, Survivors

\footnotetext{
*Correspondence: myhsiao@ntu.edu.tw

'Department of Physical Medicine and Rehabilitation, National Taiwan

University Hospital, 7, Zhongshan S. Rd., Taipei, Taiwan

${ }^{3}$ Department of Physical Medicine and Rehabilitation, College of Medicine,

National Taiwan University, 7, Zhongshan S. Rd., Taipei, Taiwan

Full list of author information is available at the end of the article
}

(c) The Author(s). 2021 Open Access This article is licensed under a Creative Commons Attribution 4.0 International License, which permits use, sharing, adaptation, distribution and reproduction in any medium or format, as long as you give appropriate credit to the original author(s) and the source, provide a link to the Creative Commons licence, and indicate if changes were made. The images or other third party material in this article are included in the article's Creative Commons licence, unless indicated otherwise in a credit line to the material. If material is not included in the article's Creative Commons licence and your intended use is not permitted by statutory regulation or exceeds the permitted use, you will need to obtain permission directly from the copyright holder. To view a copy of this licence, visit http://creativecommons.org/licenses/by/4.0/ The Creative Commons Public Domain Dedication waiver (http://creativecommons.org/publicdomain/zero/1.0/) applies to the data made available in this article, unless otherwise stated in a credit line to the data. 


\section{Background}

Primary intracerebral hemorrhage $(\mathrm{ICH})$ is the second most common type of stroke, accounting for $10-30 \%$ of all cases [1]. The incidence rate of primary ICH was estimated to be 22 per 100,000 person-year in low- to middle-income countries and 10 per 100,000 person-year in high-income countries between 1970 and 2008 [1]. Globally, between 1990 and 2013, the age-adjusted prevalence of hemorrhagic stroke remained stationary, but the ageadjusted mortality of hemorrhagic stroke decreased [2], resulting in an enhanced survival rate. However, many ICH survivors have neurological and functional impairment, requiring long-term inpatient or outpatient rehabilitation. In 2015, a population-based study revealed that only $14 \%$ of the patients with primary $\mathrm{ICH}$ achieved functional independence, defined as a modified Rankin Scale (mRS) score of $\leq 2$, at 1 year [3].

The computed tomography angiography (CTA) spot sign was first described in 1999 when the investigators found that the extravasation of radiographic contrast was an independent predictor of mortality in patients with primary $\mathrm{ICH}$ [4]. Strict radiological criteria and scoring system have been developed to better identify and quantify the spot sign [5]. In 2019, a meta-analysis revealed a high area under the receiver operating characteristic curve for $\mathrm{ICH}$ growth and mortality ( 0.86 and 0.87 , respectively), indicating good sensitivity and specificity of the spot sign to predict these outcomes [6].

Since its first report, many studies have attempted to establish the outcome prediction value of the CTA spot sign. Several studies have demonstrated the association of the CTA spot sign with higher mortality rates [7-9] and the predictive value of the spot sign in hematoma expansion $[10,11]$ in patients with primary ICH. The CTA spot sign is also associated with higher mRS scores at 3 months [79], and it serves as a predictor of re-bleeding after endoscopic surgery for $\mathrm{ICH}$ [12]. In addition, the spot sign may serve as a marker for potential candidates of early hemostatic therapy after ICH. Several trials using tranexamic acid and recombinant activated factor VII are ongoing or have been recently completed [13, 14].

Despite these insights, earlier studies on the CTA spot sign and functional outcomes are limited. These studies used mRS as the only measure of functional outcome, and the calculation of mRS included patients who died $(\mathrm{mRS}=6)$ in the acute phase of the disease [9, 15]. Additional evaluation of the association between the CTA spot sign and activities of daily living (ADL) functions in $\mathrm{ICH}$ survivors is warranted. Furthermore, the predictive value of the CTA spot sign for other ICH-related outcomes such as length of hospital stay or requirement of surgical intervention remains unestablished. This has an important clinical implication: the CTA spot sign can serve to identify $\mathrm{ICH}$ survivors with worse ADL functions at discharge, potentially experiencing longterm disabilities, and who are primary candidates for post-acute rehabilitation.

In the present study, we investigated the frequency of the CTA spot sign and its association with outcomes at hospital discharge, focusing primarily on independency in ADL, among $\mathrm{ICH}$ survivors.

\section{Methods}

Patients

We performed a retrospective analysis of consecutive patients with $\mathrm{ICH}$ admitted to the rehabilitation, neurology, or neurosurgery ward who were receiving CTA within $24 \mathrm{~h}$ from presentation to admission to the emergency department of a single medical center between January 2007 and December 2017. Patients who died before discharge, were younger than 20 years, and were referred from other hospitals were excluded. CTA with motion artifacts was also excluded from the analysis. Patients with etiologies other than primary ICH (e.g., aneurysm rupture, arteriovenous malformation, and tumor bleeding) were excluded.

\section{Image acquisition}

The scanning protocol included a pre-contrast scan and multiphase CT Angiography. CT angiography was performed by using multiple scanners, including 64-, 128-, and 320-section machines (General Electric Medical Systems and Siemens). Timing-bolus technique was used for optimal enhancement. The CT angiography injection protocol included 60-75 $\mathrm{mL}$ of contrast medium (Ultravist 370 [iopromide; Bayer, Leverkusen, Germany] or Omnipaque 350 [iohexol; GE Healthcare, Chicago, Illinois]) injected for $15 \mathrm{~s}$ at a flow rate of $4-5 \mathrm{~mL} / \mathrm{s}$, followed by a 20 $\mathrm{mL}$ saline solution chaser through a 20-gauge venous catheter. A 3-phase CT angiogram was acquired, with a 2-s interval between scans. The first phase covered the area from the aortic arch to the vertex, and the subsequent 2 phases covered the cranium only. The delayed-phase CTA images were acquired to survey delayed spot signs as well as to exclude dural venous sinus thrombosis, which is also a common cause of intracerebral hemorrhage, or other spot sign mimics such as tiny aneurysms. The CT angiographic image was reformatted into $0.625-\mathrm{mm}$ 
axial and 1-mm sagittal and coronal images. Delayed-phase $0.625-\mathrm{mm}$ axial images were also available.

\section{Outcome measures}

The presence of a spot sign was retrospectively examined by an experienced neuroradiologist, who was blinded to patient data, and the spot sign score Appendix, Table 5) was calculated. Functional outcomes were determined based on the mRS score and Barthel Index (BI) at discharge (Appendix, Table 3 and 4). Severe dependency in ADL was defined as $\mathrm{BI}$ of $\leq 60$ and severe disability was defined as an $\mathrm{mRS}$ score of $\geq 4$. Functional independence was defined as a BI of $>90$ or an mRS score of $\leq 2$. All $\mathrm{mRS}, \mathrm{BI}$, and ADL were calculated by the primary care physicians. The number of patients who received related brain surgery or ventriculostomy and the length of hospitalization were also analyzed.

\section{Statistical analyses}

The data was analyzed with Stata Statistical Software 14.0 (StataCorp LP., College Station, Texus, USA). Patient demographics and baseline characteristics were analyzed using descriptive statistics and are presented as mean \pm SD or percentage. Pearson's chi-squared test or the Fisher's exact test was used to examine the association between categorical variables, and the $t$-test was used to examine the association between numerical variables and the spot sign. Multiple linear regression was used to assess the association between the spot sign and clinical outcomes. A $p$ value of $<0.05$ was considered statistically significant.

\section{Results}

A total of 6602 patient records and brain images were reviewed, and 66 patients met the inclusion criteria (Fig. 1).

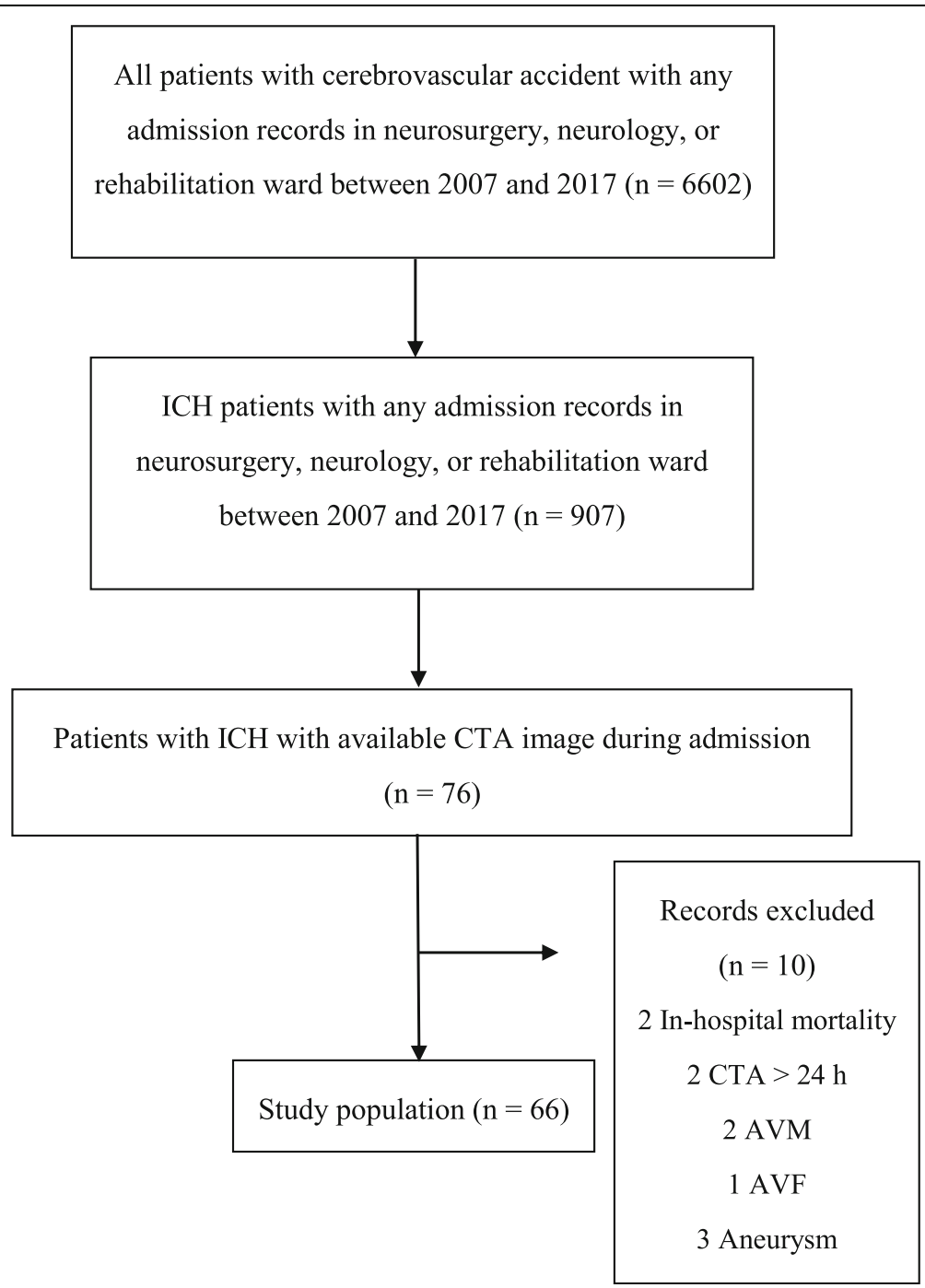

Fig. 1 Diagram of patient selection 
Table 1 Baseline characteristics of the population $(n=66)$

\begin{tabular}{|c|c|}
\hline Variables & $N(\%$ or $S D)$ \\
\hline Age (years) & $55.56(14.85)$ \\
\hline \multicolumn{2}{|l|}{ Gender } \\
\hline Female & $24(36.36)$ \\
\hline Male & $42(63.64)$ \\
\hline \multicolumn{2}{|l|}{ GCS at admission } \\
\hline $3-8$ & $12(18.18)$ \\
\hline $9-13$ & $18(27.27)$ \\
\hline $14-15$ & $36(54.55)$ \\
\hline Presence of spot sign & $9(13.64)$ \\
\hline \multicolumn{2}{|l|}{ Spot sign score } \\
\hline 1 & $3(33.33)$ \\
\hline 2 & $3(33.33)$ \\
\hline 3 & $2(22.22)$ \\
\hline 4 & $1(11.11)$ \\
\hline Bl at admission & $19.17(20.56)$ \\
\hline $\mathrm{Bl}$ at discharge & $62.77(25.77)$ \\
\hline \multicolumn{2}{|l|}{ Severe dependency } \\
\hline $\mathrm{Bl} \leq 60$ & $29 / 65(44.62)$ \\
\hline $\mathrm{mRS} \geq 4$ & $25(37.88)$ \\
\hline \multicolumn{2}{|l|}{ Functional independence } \\
\hline $\mathrm{mRS} \leq 2$ & $7 / 66(10.61)$ \\
\hline $\mathrm{Bl}>90$ & 10/66 (15.15) \\
\hline Length of hospitalization (days) & $42.15(25.37)$ \\
\hline
\end{tabular}

N Number, SD Standard deviation, GCS Glasgow Coma Scale, BI Barthel Index, $m R S$ modified Rankin Scale

Among primary ICH survivors, 9 (13.64\%) had a spot sign (Table 1). On average, BI improved from a mean of 19.17 to 62.77 during a mean of 42.15 days of hospitalization. Less than half $(29 ; 44.62 \%)$ of the patients were severely dependent in ADL at discharge, and only 10 patients $(15.15 \%)$ achieved functional independence, as assessed by BI $\leq 60$ or $>90$, respectively.

No significant differences were observed in age, sex, and BI and Glasgow coma scale (GCS) score at admission between patients with and without a spot sign (Table 2). Regarding functional status, patients with a spot sign tended to be severely dependent in ADL $(\mathrm{BI} \leq 60)$ at discharge $(66.67 \%$ vs $41.07 \%$; odds ratio $[\mathrm{OR}]=2.87 ; p=0.15$ ) and were more likely to have profound disability (mRS score $\geq 4) \quad(55.56 \%$ vs $35.09 \%$; OR $=2.31 ; p=0.24$; Fig. 2). All the patients who achieved functional independence $(n=10$, defined by $\mathrm{BI}>90$; or $n=7$ defined by $\mathrm{mRS}$ score $\leq 2$ ) were negative for the spot sign (Fig. 2).
In addition, two-thirds of the patients positive for a spot sign received surgery compared with only one-fourth of those negative for a spot sign $(66.67 \%$ vs $24.56 \%$; $\mathrm{OR}=6.14 ; p=0.01$ ). In multiple linear regression adjusted for age and sex, a higher spot sign score was significantly associated with a longer hospital stay (coefficient $=9.57 ; 95 \% \mathrm{CI}=2.11-17.03 ; p=0.013$ ).

\section{Discussion}

\section{Spot sign and functional outcomes}

This study is the first to focus on the association of the spot sign and functional outcomes in primary ICH survivors. Our results demonstrated that patients with a spot sign tended to be severely dependent in ADL at discharge and were more likely to require surgical intervention. In addition, patients with a higher spot sign score had a significantly longer hospital stay. ICH survivors, whose numbers are steadily increasing over the decades, are candidates for long-term neuro-rehabilitation, and analyses focusing on this group have important clinical implications. Detection of a spot sign may have great benefit for designing personalized and intense rehabilitation programs for ICH survivors.

Our results demonstrated that in primary $\mathrm{ICH}$ survivors, the presence of a spot sign within $24 \mathrm{~h}$ of ICH onset may be associated with detrimental functional status at discharge. Although the data did not reach statistical significance, notably, none of the patients positive for a spot sign achieved functional independence. Earlier studies have revealed that the spot sign is associated with higher mortality, hematoma expansion, and worse functional outcomes in patients with $\mathrm{ICH}$, indicating the predictive value of the spot sign. However, these studies determined the endpoint of functional outcome solely based on the mRS score and the study population included patients who died $(m R S=6)$ during the acute disease phase, which might obscure the predictability of the spot sign in $\mathrm{ICH}$ survivors $[9,15]$. In the present study, we determined functional outcomes based on both BI and $\mathrm{mRS}$ scores, which are better in characterizing ADLs. Both parameters revealed that patients with a spot sign tended to have worse outcomes (BI: $\mathrm{OR}=2.87, p=0.15 ; \mathrm{mRS}: \mathrm{OR}=2.31 ; p=0.24)$. The OR for worse outcome defined based on the mRS score $(\geq 4)$ was similar to previous studies, which reported ORs of 2.40 and $2.50[7,9]$. The nonsignificance of the OR in the present study could be attributed to the small sample size, due to strict inclusion/exclusion criteria, and the selection of patients admitted to rehabilitation, neurology, and neurosurgery wards to retrieve consistent functional evaluation records. 
Table 2 Comparison between ICH survivors with or without a spot sign $(n=66)$

\begin{tabular}{|c|c|c|c|c|}
\hline Variables & $\begin{array}{l}\text { Spot sign negative }(n=57) \\
N(\% \text { or } S D)\end{array}$ & $\begin{array}{l}\text { Spot sign positive }(n=9) \\
N(\% \text { or } S D)\end{array}$ & $P$-value & Odds Ratio (OR) \\
\hline Age (years) & $55.26(15.34)$ & $57.44(11.86)$ & 0.69 & \\
\hline Gender (female) & 20/57 (35.09) & $4 / 9(44.44)$ & 0.59 & \\
\hline GCS at admission & & & 0.85 & \\
\hline $3-8$ & $11(19.30)$ & $1(11.11)$ & & \\
\hline $9-13$ & $14(24.56)$ & $4(44.44)$ & & \\
\hline $14-15$ & $32(56.14)$ & $4(44.44)$ & & \\
\hline Bl at admission & $19.39(18.15)$ & $17.78(33.55)$ & 0.41 & \\
\hline $\mathrm{Bl}$ at discharge (mean) & $63.39(27.05)$ & $58.89(16.16)$ & 0.32 & \\
\hline \multicolumn{5}{|l|}{ Severe dependency } \\
\hline $\mathrm{Bl} \leq 60$ & $23 / 56(41.07)$ & 6/9 (66.67) & 0.15 & $2.8^{\mathrm{a}}$ \\
\hline$m R S \geq 4$ & 20/56 (35.09) & $5 / 9(55.56)$ & 0.24 & $2.31^{\mathrm{a}}$ \\
\hline \multicolumn{5}{|l|}{ Functional independence } \\
\hline $\mathrm{Bl}>90$ & 10/57 (17.54) & $0 / 9(0)$ & 0.17 & - \\
\hline$m R S \leq 2$ & $7 / 57(12.28)$ & $0 / 9(0)$ & 0.34 & - \\
\hline Surgery & $14 / 57(24.56)$ & $6 / 9(66.67)$ & 0.01 & 6.14 \\
\hline Ventriculostomy & $3 / 57(5.26)$ & $2 / 9(22.22)$ & 0.07 & 5.14 \\
\hline Length of hospitalization (days) & $39.81(24.00)$ & $55.7(30.20)$ & 0.06 & \\
\hline Hematoma expansion & $8 / 39(20.51)$ & $3 / 5(60)$ & 0.055 & \\
\hline
\end{tabular}

$N$ Number, SD Standard deviation, GCS Glasgow Coma Scale, BI Barthel Index, $m R S$ modified Rankin Scale

${ }^{\mathrm{a}}$ Odds ratio for worse outcome $(\mathrm{BI} \leq 60$ or $\mathrm{mRS}$ score $\geq 4)$

\section{Spot sign, surgery, and length of hospital stay}

Essentially, two-thirds of the patients positive for a spot sign required cranial surgery compared with only onefourth of the patients negative for a spot sign $(66.67 \%$ vs $24.56 \%, \mathrm{OR}=6.14 ; p=0.01)$. Indication for surgery is often an ominous sign of the profound mass effect of hematoma, although numerous factors, such as location of hematoma and baseline condition of patients, may confound the decision. On the contrary, although the benefit of surgery in terms of mortality and functional outcomes remains unclear in primary ICH [16], recent studies have reported that early neurosurgery is predictive of longer survival and better functional outcomes in patients with severe primary ICH [17]. Thus, early identification of patients with ICH in whom surgical intervention has a positive impact is of great clinical importance.

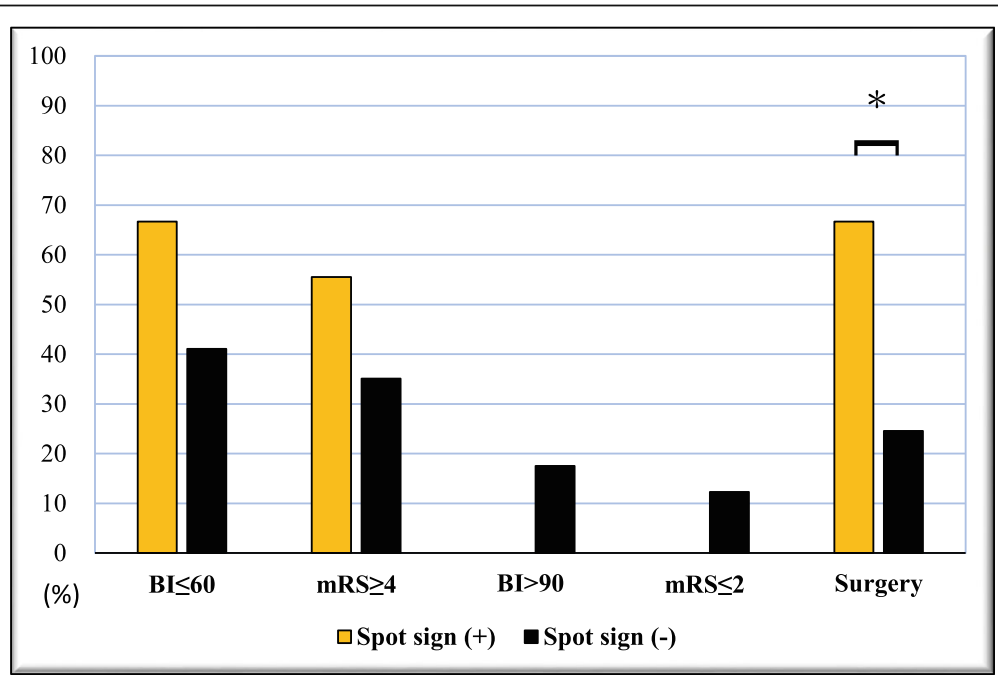

Fig. 2 Functional outcomes of patients with or without a spot sign. ${ }^{*} p<0.05$ 
In addition to functional outcomes, multiple linear regression demonstrated that patients with a higher spot sign score had a longer mean hospital stay $(p=0.013)$. Essentially, all the patients in this study were covered by the National Health Insurance program, which covers 99.9\% of the citizens of Taiwan, attenuating the influence of private health insurance and socioeconomic status on the length of hospital stay. The duration of hospitalization may reflect the severity of diseases, complications rates, and medical costs. Furthermore, studies in geriatric and general populations indicate that prolonged hospitalization is associated with increased functional dependence, infection, and comorbidities [18-20].

\section{Implications}

Early CTA serves as an important tool to diagnose and evaluate $\mathrm{ICH}$, and an earlier study reported that a CTA spot sign could be precisely detected across multiple medical centers [21]. Extending its association with functional outcomes, as is shown in our results, the spot sign is a potential indicator for prognosis in patients with primary $\mathrm{ICH}$. Furthermore, the spot sign helps identify $\mathrm{ICH}$ survivors who might require surgical intervention and longer in-patient treatment course. Combining the CTA spot sign with other prognostic tools is also an option [15], but more research on this topic is warranted.

\section{Limitations}

This study has several limitations. First, the sample size was relatively small. CTA was not routinely performed in patients with $\mathrm{ICH}$. Limited case number hinders further stratification according to BI and mRS scores. Second, the followup period was short and not standardized in all the patients because of the retrospective study design. Further large-scale prospective studies with longer follow-up durations are warranted to comprehensively verify the predictive value of the spot sign. Third, in our retrospective review, we found no clear protocol for when and on whom to perform CTA in patients with ICH. CTA was performed when the cerebral hemorrhage seemed atypical for primary hypertensive $\mathrm{ICH}$, which was determined by neurologists or neurosurgeons. This could have caused a selection bias that not all patients with primary ICH have CTA data available, and the criteria for prescribing a CTA may differ between physicians. Despite these limitations, our study still provides important evidence of the association of an early spot sign and deleterious outcomes in primary ICH survivors.

\section{Conclusions}

The presence of a spot sign is a common finding and is associated with longer hospital stay and possibly worse functional outcomes in ICH survivors. This study provides important evidence of the association of an early CTA spot sign and deleterious outcomes in primary $\mathrm{ICH}$ survivors.

\section{Appendix}

Table 3 Barthel index

\begin{tabular}{|c|c|}
\hline Activity & Score \\
\hline \multirow[t]{3}{*}{ Feeding } & $0=$ unable \\
\hline & $\begin{array}{l}5=\text { needs help cutting, spreading butter, etc., or requires } \\
\text { modified diet }\end{array}$ \\
\hline & $10=$ independent \\
\hline \multirow[t]{2}{*}{ Bathing } & $0=$ dependent \\
\hline & $5=$ independent (or in shower) \\
\hline \multirow[t]{2}{*}{ Grooming } & $0=$ needs to help with personal care \\
\hline & 5 = independent face/hair/teeth/shaving (implements provided) \\
\hline \multirow[t]{3}{*}{ Dressing } & $0=$ dependent \\
\hline & $5=$ needs help but can do about half unaided \\
\hline & $10=$ independent (including buttons, zips, laces, etc.) \\
\hline \multirow[t]{3}{*}{ Bowels } & $0=$ incontinent (or needs to be given enemas) \\
\hline & 5 = occasional accident \\
\hline & $10=$ continent \\
\hline \multirow[t]{3}{*}{ Bladder } & $0=$ incontinent or catheterized and unable to manage alone \\
\hline & $5=$ occasional accident \\
\hline & $10=$ continent \\
\hline \multirow[t]{3}{*}{ Toilet } & $0=$ dependent \\
\hline & $5=$ needs some help, but can do something alone \\
\hline & 10 = independent (on and off, dressing, wiping) \\
\hline \multirow[t]{4}{*}{ Transfer } & $0=$ unable, no sitting balance \\
\hline & $5=$ major help (one or two people, physical), can sit \\
\hline & $10=$ minor help (verbal or physical) \\
\hline & $15=$ independent \\
\hline \multirow[t]{4}{*}{ Ambulation } & $0=$ immobile or $<50$ yards \\
\hline & $5=$ wheelchair independent, including corners, $>50$ yards \\
\hline & $\begin{array}{l}10=\text { walks with help of one person (verbal or physical) } \\
>50 \text { yards }\end{array}$ \\
\hline & $\begin{array}{l}15=\text { independent (but may use any aid; for example, stick) } \\
>50 \text { yards }\end{array}$ \\
\hline \multirow[t]{3}{*}{ Stairs } & $0=$ unable \\
\hline & $5=$ needs help (verbal, physical, carrying aid) \\
\hline & $10=$ independent \\
\hline
\end{tabular}

Table 4 Modified Rankin scale

\begin{tabular}{ll}
\hline Score & Definition \\
\hline 0 & No symptoms \\
1 & $\begin{array}{l}\text { No significant disability. Able to carry out all usual activities, despite } \\
\text { some symptoms. }\end{array}$ \\
2 & $\begin{array}{l}\text { Slight disability. Able to look after own affairs without assistance, but } \\
\text { unable to carry out all previous activities. }\end{array}$ \\
3 & $\quad \begin{array}{l}\text { Moderate disability. Requires some help, but able to walk unassisted. } \\
\text { Moderately severe disability. Unable to attend to own bodily needs }\end{array}$ \\
5 & $\begin{array}{l}\text { Sithout assistance, and unable to walk unassisted. } \\
\text { bedridden, incontinent. }\end{array}$ \\
6 & Dead.
\end{tabular}


Table 5 Spot sign score

\begin{tabular}{ll}
\hline Definition & Point \\
\hline Number of spot signs & 1 \\
$1-2$ & 2 \\
$\geq 3$ & \\
Maximum axial dimension & 0 \\
$1-4 \mathrm{~mm}$ & 1 \\
$\geq 5 \mathrm{~mm}$ & \\
Maximum attenuation & 0 \\
$120-179 \mathrm{HU}$ & 1 \\
$\geq 180 \mathrm{HU}$ & \\
\hline
\end{tabular}

\section{Abbreviations}

ADL: Activities of daily living; BI: Barthel Index; CTA: Computed tomography angiography; GCS: Glasgow coma scale; ICH: Intracerebral hemorrhage; mRS: Modified Rankin Scale; OR: Odds ratio

\section{Acknowledgements}

The abstract of this study was published in the 2020 International Society of Physical and Rehabilitation Medicine (ISPRM) world congress and annual meeting of the association of academic physiatrists [22].

\section{Authors' contributions}

WCT run the statistical analyses, wrote the first draft of the manuscript, and applied for the funding; YFW read the CTA images and calculated the spot sign score; TGW was responsible for the study design and the application for the data; MYH was responsible for the IRB approval and manuscript revision. The author(s) read and approved the final manuscript.

\section{Funding}

This research was supported by grants from the National Taiwan University Hospital (grant \#109-N4458).

\section{Availability of data and materials}

The datasets used and/or analysed during the current study are available from the corresponding author on reasonable request.

\section{Declarations}

\section{Ethics approval and consent to participate}

This study was approved by Institutional Review Board of National Taiwan University Hospital (No.201806049RINC). All procedures and analyses performed in the present study were in accordance with the ethical standards of the institutional and/or national research committee and with the 1964 Helsinki declaration and its later amendments or comparable ethical standards. This study as approved by the hospital's institutional review board for waiving the informed consent.

\section{Consent for publication}

Not applicable.

\section{Competing interests}

The authors declare that they have no competing interests.

\section{Author details}

'Department of Physical Medicine and Rehabilitation, National Taiwan University Hospital, 7, Zhongshan S. Rd., Taipei, Taiwan. ${ }^{2}$ Department of Medical Imaging, National Taiwan University Hospital, 7, Zhongshan S. Rd., Taipei, Taiwan. ${ }^{3}$ Department of Physical Medicine and Rehabilitation, College of Medicine, National Taiwan University, 7, Zhongshan S. Rd., Taipei, Taiwan.
Received: 3 August 2020 Accepted: 8 March 2021

Published online: 20 March 2021

\section{References}

1. Feigin VL, Lawes CM, Bennett DA, Barker-Collo SL, Parag V. Worldwide stroke incidence and early case fatality reported in 56 population-based studies: a systematic review. Lancet Neurol. 2009;8(4):355-69. https://doi. org/10.1016/S1474-4422(09)70025-0.

2. Feigin VL, Krishnamurthi RV, Parmar P, Norrving B, Mensah GA, Bennett DA, Barker-Collo S, Moran AE, Sacco RL, Truelsen T, Davis S, Pandian JD, Naghavi M, Forouzanfar MH, Nguyen G, Johnson CO, Vos T, Meretoja A, Murray CJ, Roth GA, GBD 2013 Writing Group, GBD 2013 Stroke Panel Experts Group. Update on the global burden of ischemic and hemorrhagic stroke in 19902013: the GBD 2013 study. Neuroepidemiology. 2015;45(3):161-76. https:// doi.org/10.1159/000441085.

3. Samarasekera N, Fonville A, Lerpiniere C, Farrall AJ, Wardlaw JM, White PM Smith C, Al-Shahi Salman R. Influence of intracerebral hemorrhage location on incidence, characteristics, and outcome: population-based study. Stroke. 2015;46(2):361-8. https://doi.org/10.1161/STROKEAHA.114.007953.

4. Becker KJ, Baxter AB, Bybee HM, Tirschwell DL, Abouelsaad T, Cohen WA. Extravasation of radiographic contrast is an independent predictor of death in primary intracerebral hemorrhage. Stroke. 1999;30(10):2025-32. https:// doi.org/10.1161/01.STR.30.10.2025.

5. Delgado Almandoz JE, Yoo AJ, Stone MJ, Schaefer PW, Goldstein JN, Rosand J, Oleinik A, Lev MH, Gonzalez RG, Romero JM. Systematic characterization of the computed tomography angiography spot sign in primary intracerebral hemorrhage identifies patients at highest risk for hematoma expansion: the spot sign score. Stroke. 2009;40(9):2994-3000. https://doi. org/10.1161/STROKEAHA.109.554667.

6. Phan TG, Krishnadas N, Lai WWY, Batt M, Slater LA, Chandra RV, Srikanth V, $\mathrm{Ma} \mathrm{H}$. Meta-analysis of accuracy of the spot sign for predicting hematoma growth and clinical outcomes. Stroke. 2019;50(8):2030-6. https://doi.org/1 0.1161/STROKEAHA.118.024347

7. Delgado Almandoz JE, Yoo AJ, Stone MJ, Schaefer PW, Oleinik A, Brouwers HB, Goldstein JN, Rosand J, Lev MH, Gonzalez RG, Romero JM. The spot sign score in primary intracerebral hemorrhage identifies patients at highest risk of in-hospital mortality and poor outcome among survivors. Stroke. 2010; 41(1):54-60. https://doi.org/10.1161/STROKEAHA.109.565382.

8. Demchuk AM, Dowlatshahi D, Rodriguez-Luna D, Molina CA, Blas YS, Dzialowski I, Kobayashi A, Boulanger JM, Lum C, Gubitz G, Padma V, Roy J, Kase CS, Kosior J, Bhatia R, Tymchuk S, Subramaniam S, Gladstone DJ, Hill MD, Aviv RI, PREDICT/Sunnybrook ICH CTA study group. Prediction of haematoma growth and outcome in patients with intracerebral haemorrhage using the CT-angiography spot sign (PREDICT): a prospective observational study. Lancet Neurol. 2012;11(4):307-14. https://doi.org/10.101 6/S1474-4422(12)70038-8.

9. Havsteen I, Ovesen C, Christensen AF, Hansen CK, Nielsen JK, Christensen H. Showing no spot sign is a strong predictor of independent living after intracerebral haemorrhage. Cerebrovasc Dis (Basel, Switzerland). 2014;37(3): 164-70.

10. Wada R, Aviv RI, Fox AJ, Sahlas DJ, Gladstone DJ, Tomlinson G, Symons SP. CT angiography "spot sign" predicts hematoma expansion in acute intracerebral hemorrhage. Stroke. 2007;38(4):1257-62. https://doi.org/10.11 61/01.STR.0000259633.59404.f3.

11. Hallevi H, Abraham AT, Barreto AD, Grotta JC, Savitz SI. The spot sign in intracerebral hemorrhage: the importance of looking for contrast extravasation. Cerebrovasc Dis (Basel, Switzerland). 2010;29(3):217-20.

12. Miki $K$, Yagi $K$, Nonaka M, Iwaasa M, Abe H, Morishita T, Arima H, Inoue T. Spot sign as a predictor of rebleeding after endoscopic surgery for intracerebral hemorrhage. J Neurosurg. 2018:1-6. https://doi.org/10.3171/2 017.12.JNS172335.

13. Meretoja A, Churilov L, Campbell BC, Aviv RI, Yassi N, Barras C, Mitchell P, Yan B, Nandurkar H, Bladin C, et al. The spot sign and tranexamic acid on preventing ICH growth--AUStralasia Trial (STOP-AUST): protocol of a phase II randomized, placebo-controlled, double-blind, multicenter trial. Int J Stroke. 2014;9(4):519-24. https://doi.org/10.1111/ijs.12132.

14. Gladstone DJ, Aviv RI, Demchuk AM, Hill MD, Thorpe KE, Khoury JC, Sucharew HJ, Al-Ajlan F, Butcher K, Dowlatshahi D, et al. Effect of recombinant activated coagulation factor VII on hemorrhage expansion among patients with spot sign-positive acute Intracerebral hemorrhage: the 
SPOTLIGHT and STOP-IT randomized clinical trials. JAMA Neurol. 2019;76(12): 1493. https://doi.org/10.1001/jamaneurol.2019.2636.

15. Schneider H, Huynh TJ, Demchuk AM, Dowlatshahi D, Rodriguez-Luna D, Silva Y, Aviv R, Dzialowski I. Combining spot sign and intracerebral hemorrhage score to estimate functional outcome: analysis from the PRED ICT cohort. Stroke. 2018;49(6):1511-4. https://doi.org/10.1161/STROKEAHA.11 8.020679 .

16. de Oliveira Manoel AL. Surgery for spontaneous intracerebral hemorrhage. Crit Care (London, England). 2020;24(1):45.

17. Ferrete-Araujo AM, Egea-Guerrero JJ, Vilches-Arenas A, Godoy DA, MurilloCabezas F. Predictors of mortality and poor functional outcome in severe spontaneous intracerebral hemorrhage: a prospective observational study. Med Int. 2015;39(7):422-32

18. Toh HJ, Lim ZY, Yap P, Tang T. Factors associated with prolonged length of stay in older patients. Singap Med J. 2017;58(3):134-8. https://doi.org/10.11 622/smedj.2016158.

19. Marfil-Garza BA, Belaunzaran-Zamudio PF, Gulias-Herrero A, Zuniga AC, Caro-Vega Y, Kershenobich-Stalnikowitz D, Sifuentes-Osornio J. Risk factors associated with prolonged hospital length-of-stay: 18-year retrospective study of hospitalizations in a tertiary healthcare center in Mexico. PLoS One. 2018;13(11):e0207203. https://doi.org/10.1371/journal.pone.0207203.

20. Shayne M, Culakova E, Poniewierski MS, Dale DC, Crawford J, Wogu AF, Lyman GH. Risk factors for in-hospital mortality and prolonged length of stay in older patients with solid tumor malignancies. J Geriatr Oncol. 2013; 4(4):310-8. https://doi.org/10.1016/j.jgo.2013.05.005.

21. Huynh TJ, Flaherty ML, Gladstone DJ, Broderick JP, Demchuk AM, Dowlatshahi D, Meretoja A, Davis SM, Mitchell PJ, Tomlinson GA, Chenkin J, Chia TL, Symons SP, Aviv Rl. Multicenter accuracy and interobserver agreement of spot sign identification in acute intracerebral hemorrhage. Stroke. 2014;45(1):107-12. https://doi.org/10.1161/STROKEAHA.113.002502.

22. Abstracts of scientific papers and posters presented at the ISPRM world congress and annual meeting of the association of academic physiatrists Orlando, Florida March 4-9, 2020. J Int Soc Phys Rehabil Med. 2020;3(5):1488

\section{Publisher's Note}

Springer Nature remains neutral with regard to jurisdictional claims in published maps and institutional affiliations.

Ready to submit your research? Choose BMC and benefit from:

- fast, convenient online submission

- thorough peer review by experienced researchers in your field

- rapid publication on acceptance

- support for research data, including large and complex data types

- gold Open Access which fosters wider collaboration and increased citations

- maximum visibility for your research: over $100 \mathrm{M}$ website views per year

At $\mathrm{BMC}$, research is always in progress.

Learn more biomedcentral.com/submissions 